\title{
CLAY-WORK IN THE UNIVERSITY ELEMENTARY SCHOOL
}

\author{
HARRIET JOOR \\ Instructor in Clay-Modeling
}

In the Elementary School the work in clay is always closely related to the other work in each grade, so that all forms of the student's activities may be brought into harmony.

The pottery is, in every case, built up by coils from a working drawing made by the pupil, and the decoration is incised in the wet clay, or modeled in very low relief; the whole piece being then covered with an opaque glaze. Very rarely, and then only in the higher grades, the design is painted on with a clay of a different color, or with slip in which color has been mixed.

The motives for the applied decoration are chosen in correlation with the pupil's school-work: thus, when the children of the third grade were studying Norse history, they decorated their bowls with arrangements of Norse shields, spears, bows, or writhing dragons.

Clay, as a medium, appeals most strongly to the younger children. It is so sensitive and pliable a material that it does not tire the smallest or weakest fingers; while the sturdiest little worker learns by degrees to control his nervous energy when he realizes that too great pressure destroys his work. That his fingers are his servants, and must learn to obey his will and work gently, even when most eager and excited, is one of the truths that the smallest clay-pupil learns very early; though his untutored muscles may be slow in rendering the obedience.

This year the pupils of the first grade began their work in clay by modeling farm animals. Later in the spring, the horses and cows and chickens will stock a miniature farm in the school garden. The same children have made in the wood-work department the barns for this farm. The animals were modeled from plaster casts and pictures; the children were questioned as to the 
animals they saw on their trips to and from the school, and were asked to note the relative sizes of the different creatures, and the proportion the head and legs (as well as any peculiar or beautiful feature, as, for instance, the splendid chest of the horse) bore to the body. In November their Christmas work was begun: very simple bowl shapes to hold nuts or short-stemmed flowers, the only decoration being an opaque glaze. In January, in connection with their study of Eskimo life, these children modeled Eskimo houses in clay; then little fur-wrapped Eskimo children, with their sleds and dogs.

The second grade, early in the school year, in connection with its study of the food-supply of mankind and its transportation, modeled fruits and vegetables in clay, then the trains, wagons, and boats used in the transportation of food-stuffs. In November it began the Christmas gifts: violet vases, low fruit bowls, candlesticks of very simple design, and teapot tiles, round and square. For decoration, some simple arrangement of leaf or berry was incised in the clay; the tiles being painted in underglaze colors; the bowls and candlesticks being simply colorglazed.

The third grade, which has been studying the story of the Odyssey, is to model during the winter quarter a series of tiles in low relief, telling the history of Ulysses' wanderings. These tiles are afterward to be set in a frame above the black-board in the classroom.

The fourth grade devoted the earlier portion of the year to the making of vases and jardinères, using for decoration whatever plant-forms were found growing in the open at the time the jar was ready for the design: berries, seed-pods, and thorny sprays, such as could be seen in the parks and vacant squares, together with the few leaf-forms that still lingered with us. During this midwinter term the class is busy making tiles for a window-box for its classroom. These tiles are later to be joined by copper frames which the children are themselves making in the metal department.

The sixth grade has been busy with Greek history and Greek literature; and for its clay-work has studied the shapes of the 
Greek vases, choosing, for decoration, motives from Greek borders. This class has had rich opportunity for the study of lines of simple dignity, and shapes of purest beauty.

The eighth grade in its history work has been tracing the origin and development of chivalry; and in its clay-work in the spring quarter will illustrate this theme in simple compositions in low relief on rectangular placques.

The fifth and seventh grades have no clay-work during the present school-year.

In the lower grades no high degree of accuracy is expected; the chief aim being to awaken a sense of proportion, and train the inexperienced fingers to obey the child's will so that his artistic impulse may find expression.

But from the fourth grade, up to the eighth, not only is more accurate craftsmanship required, but the pupil is also led to note subtle differences in lines, and to feel the charm of harmoniously varied curves; while the sheer beauty of simple, lovely forms is more fully dwelt upon.

That there is in every soul an instinctive preference for those things that are enduringly beautiful is proved again and again by the fact that in spite of the distorted and unlovely creations with which, in this commercial age, we are all surrounded, the students usually choose vase-forms of simple dignity and grace. Sometimes there is revealed a rare sensitiveness to the charm of texture, or to the pure beauty of lovely shapes. One pupil in the sixth grade gives to the surface of her vases a certain veiled quality of delicately elusive charm; while, again and again, the finer quality of appreciation is revealed in an instinctive preference for the pure shape of the jar itself, which makes the worker shrink from cutting the line of the vase by any applied decoration whatever. 


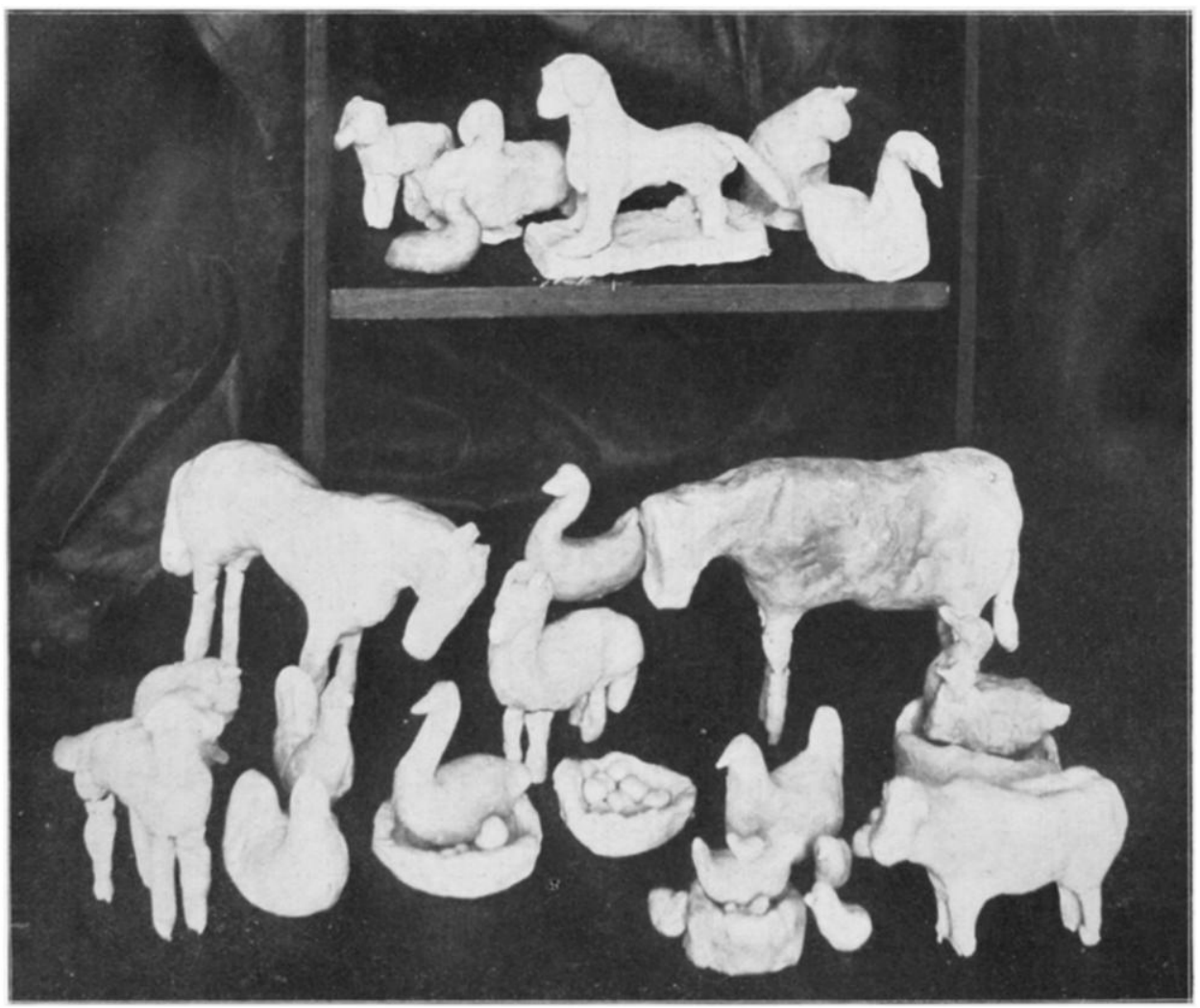

Animals Modeled to Stock a Miniature Farm in the School Garden First Grade

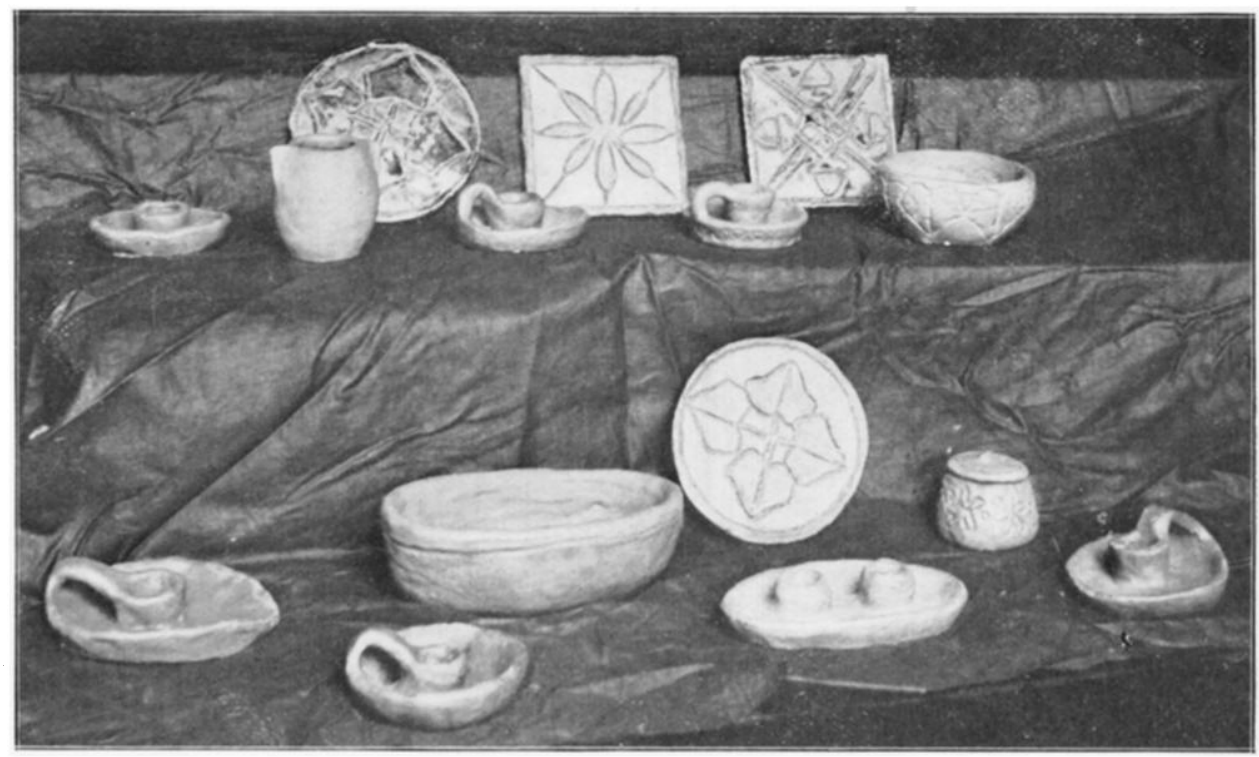

This content downloaded from 132.174.250.220 on January 17, 2018 19:06:51 PM

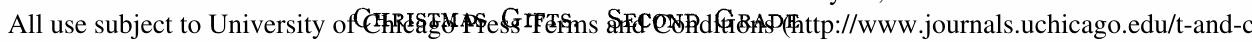




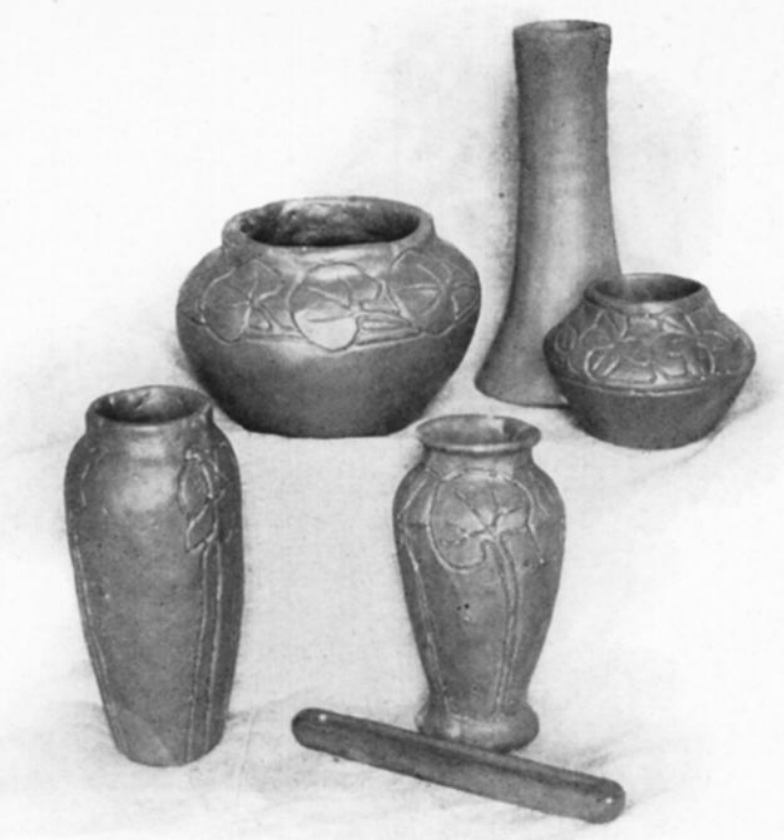

Plant-Form Decorations. Fourth Grade

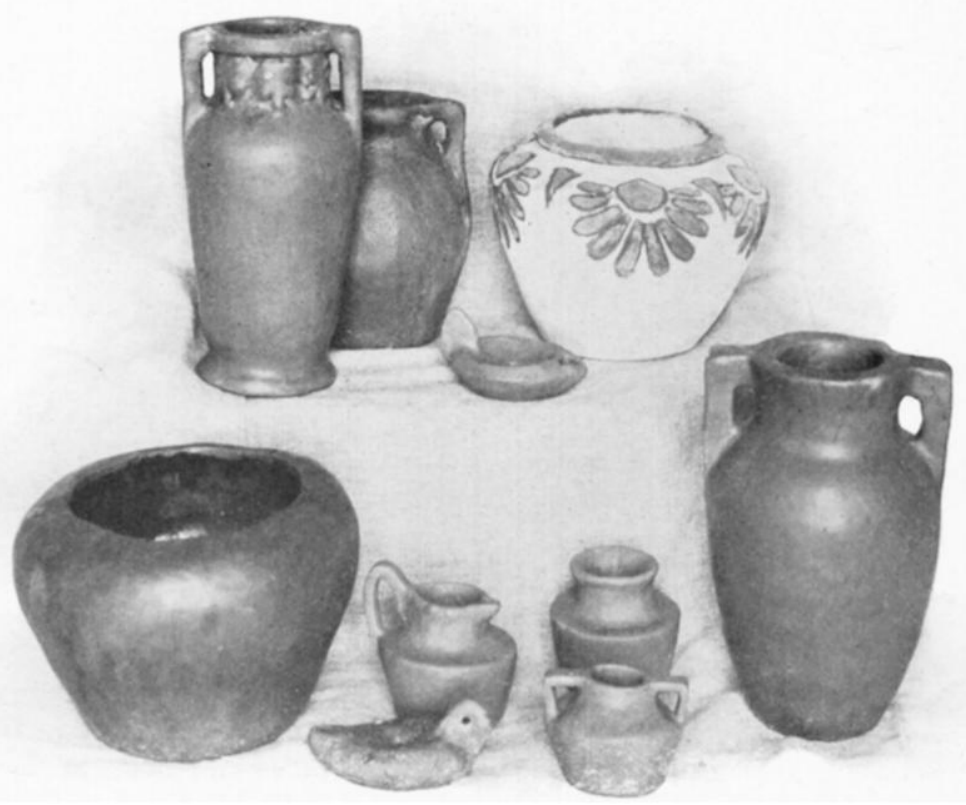

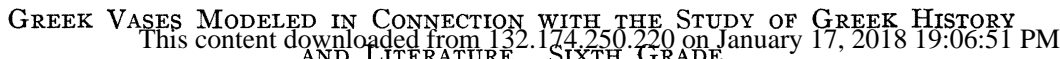
All use subject to University of Chicago Press Terms and Conditions (http://www.journals.uchicago.edu/t-and-c 